\section{Brightness contrast, brightness constancy, and the ratio principle}

\author{
ERIC G. HEINEMANN \\ Brooklyn College of the City University of New York \\ Brooklyn, New York
}

In two recent articles, Jacobsen and Gilchrist (1988a, $1988 \mathrm{~b}$ ) discussed a number of issues relating to brightness constancy and the ratio principle of brightness perception. Many of the points made in these articles are disputable. Three of the most important ones are discussed below.

1. The lightness-brightness distinction. Jacobsen and Gilchrist (1988a) revive Katz's (1935) claim that "lightness" (said to be an attribute of surface colors) and "brightness" (said to be an attribute of film colors) follow different laws. More specifically, they assert that one law, the ratio principle, applies to lightness and another, luminance matching, applies to brightness.

The principal evidence they advance in support of this claim comes from a haploscopic matching experiment in which one eye was used to view five achromatic Munsell papers of reflectances ranging from $90 \%$ to $3.1 \%$ (the test fields), surrounded by a common background of $20 \%$ reflectance. The luminances of these test fields and their background were varied over a wide range by changing the illumination on this entire array of surfaces. The other eye was presented with a comparison field surrounded by an area that either was totally dark (the brightness condition) or had a luminance of $46 \mathrm{fL}$ (the lightness condition). It was found that, as test-field luminance was increased, the curves showing the luminance necessary to match each test field rose much more steeply when the comparison field was presented on the dark background than when it was presented on the light one (see Jacobsen \& Gilchrist, 1988a, Figure 4). It is this difference that appears to be the basis for Jacobsen and Gilchrist's assumption that the subjects match for brightness when the comparison field has a dark background, and for lightness when it has a light background. However, in making this assumption, Jacobsen and Gilchrist ignore the way brightness matches are affected when the luminance of the comparison field's surround is set to various values intermediate between the two extremes examined in their experiment. These effects are shown in Figure 1, which is a replot, with some interpolation, of data published by Heinemann (1961, Figure 3, Subject J.B.). The significant feature of these results is that the matching functions do not fall into two categories that might be correlated with two distinct subjective attributes, such as lightness

The author's mailing address is Department of Psychology, Brooklyn College, City University of New York, Brooklyn, NY 11210. and brightness. Instead, the steepness of the matching curves seems to be a continuous function of the luminance of the area that surrounds the comparison field.

A somewhat similar problem exists on a purely phenomenological level. Modes of appearance of colors do not fall neatly into two classes. As Katz (1935) recognized, there is a continuum of modes ranging from surface color through degrees of filminess to foggy or bulky color (see also Fry, 1931). Thus, the phenomenological conditions under which one or the other law is assumed to apply remain unspecified.

In what appears to be a further attempt to specify the physical conditions under which the ratio principle applies, Jacobsen and Gilchrist repeatedly suggest that it applies to decrements, but not to increments (Jacobsen \& Gilchrist, 1988b, pp. 7, 8, 9, 13). Their statements to this effect always contain a qualifier (such as the word "suggests"), indicating that they are aware of difficulties. The fact is that their own work, referred to above (Jacobsen \& Gilchrist, 1988a), clearly shows that the statement is wrong. Of the five test fields used in that experiment, three were increments and two were decrements. The results obtained when the comparison field was shown on an illuminated background show that the ratio principle was approximately true for all five of these test fields. There are numerous other experiments that also show that the ratio principle holds for increments as well as decrements (e.g. Fry \& Alpern, 1953; Heinemann, 1955, 1961; also

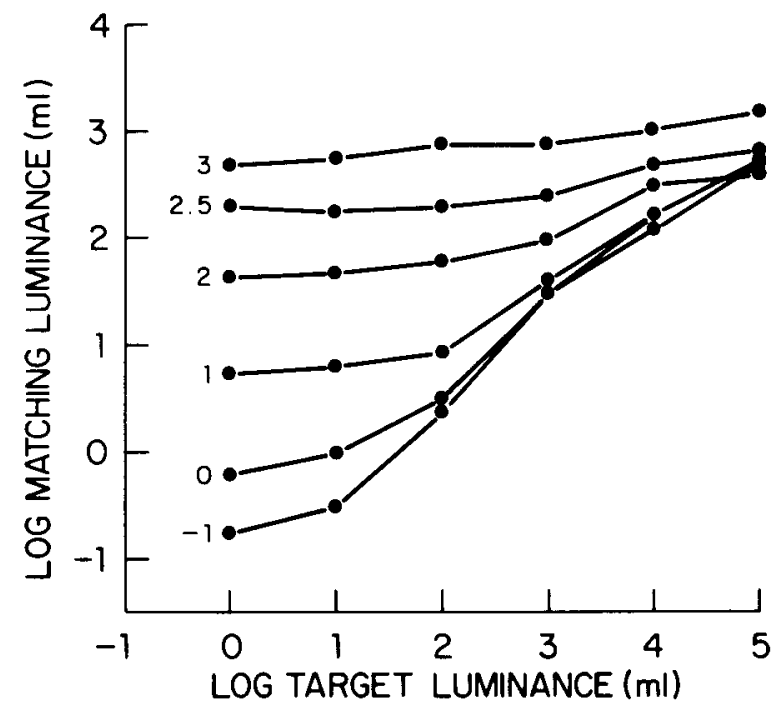

Figure 1. The comparison-field luminances required for a brightness match between the comparison and test fields as a function of test-field luminance. The luminance of the area surrounding the test field covaried with test-field luminance so as to hold the test-field/sarround luminance ratio constant at 0.6 . The parameters on the curves represent the $\log$ luminance $(\mathrm{mL})$ of the area surrounding the comparison field. (Data from Heinemann, 1961) 
discussed in Heinemann, 1972, p. 151). While the general statement that the ratio principle does not hold for increments is clearly wrong, it is true that when the ratio of test-field luminance to inducing-field luminance exceeds a value of approximately 5.0, the inducing field ceases to affect the test field. If the comparison field also is unaffected by its background, then the subjects make luminance matches under these conditions (Heinemann, $1955,1961)$.

2. On the replicability of Jameson and Hurvich's (1961) results. Jacobsen and Gilchrist (1988a) state that they were not able to replicate Jameson and Hurvich's (1961) finding that, under some circumstances, dark gray surfaces appear to darken as the illumination on them increases, and that this result is "essentially unreplicable." Since the results of Jacobsen and Gilchrist (1988a) are based on just 3 subjects and no statistical analysis was presented, the justification for the quoted statement is unclear. Results that do agree with those of Jameson and Hurvich were reported by Helson (1943), and effects of this sort also may be seen in Heinemann's (1955) data, shown in Figure 2 . In the coordinate system of Figure 2, a constant test-field/inducing-field luminance ratio is represented by a straight line of slope 1.0, exemplified by the dotted line. The manner in which this line cuts across the family of constant-brightness curves shows that, for a constant testfield/inducing-field luminance ratio, increases in absolute luminance level can result in a darkening of the test field, which is followed at still higher luminance leveis by a brightening of the test field.

3. Hess and Pretori visited once more. In their discussion of Hess and Pretori's (1894) data, Jacobsen and Gilchrist (1988b) begin by wondering why Hess and Pretori did not discover the ratio principle that they credit to Wallach (1948). There is really no puzzle, because the results obtained by Hess and Pretori and those obtained by Wallach, under the conditions common to the two experiments, are virtually identical. The data of Hess and Pretori (1894) are shown in Figure 3, reproduced from Jaensch and Müller (1920). The lines in this graph represent contours of constant brightness (i.e., combinations of surround and test-field luminances for which the test field has a constant brightness). The ratio principle would be represented by a family of straight lines passing through the origin, with the slope of each line representing a specific test-field/surround luminance ratio. Hess and Pretori's investigation covered a very much wider range of luminance ratios than did Wallach's. The ratios investigated by Wallach are represented roughly by lines 11 and 12 in Hess and Pretori's figure. Note that these lines pass close to the origin of the coordinate system, therefore, the ratio principle applies, and there is no conflict whatsoever with the results of Wallach. (Hess and Pretori fitted straight lines to their data, but the extension of these lines to another quadrant was added by Jaensch and Müller, 1920. It is of some interest that, if the coordinate system were translated so as to place the intersection of all the lines at the new origin, the ratio principle would be generally true with respect to the new coordinates.)

Lines of very steep slope, such as lines 2,3 , and 4 in Figure 3, represent situations in which the inducing-field luminance is very much greater than the test-field luminance. Under these circumstances, the test-field appears dark gray or black. Jacobsen and Gilchrist (1988b) argue that such data as those represented by lines 2,3 , and 4 must represent an elaborate artifact, because the test fields under consideration all appear black, and further reduction of each test field's luminance will not make it appear any blacker. The situation may be clarified by reference to Figure 2, which shows data from Heinemann

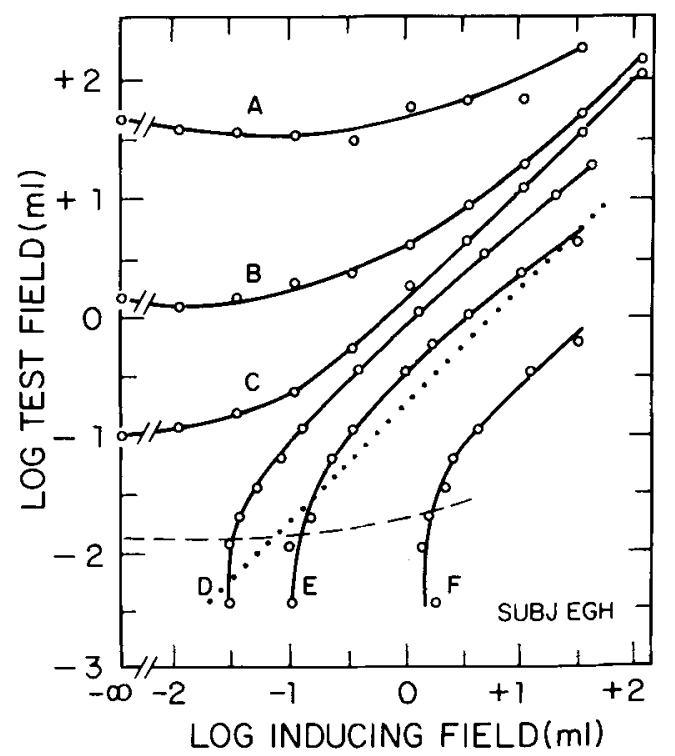

Figure 2. The test-field luminance needed to match a comparison field of fixed brightness as a function of the luminance of the inducing field. Each curve represents a constant level of brightness, ranging from moderately bright (curves $A$ and B) to very dark gray or black (curves $E$ and F). (After Heinemann, 1955) 


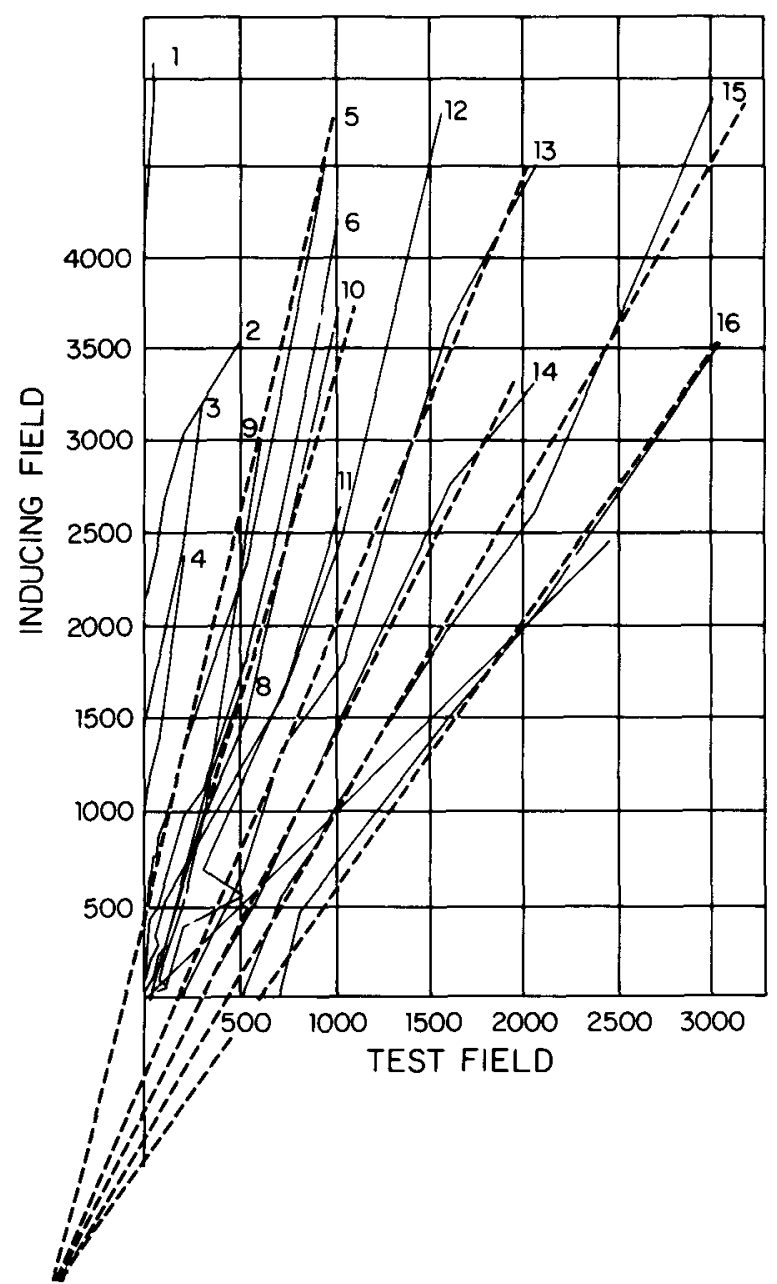

Figure 3. Contours of constant brightness obtained by Hess and Pretori (1894). (After Jaensch \& Müller, 1920)

(1955), plotted in the fashion of Hess and Pretori, but on logarithmic stimulus scales.

Curves D, E, and F are contours of constant brightness representing test fields that appear dark gray or black, and are comparable to the contours discussed in the previous paragraph. Note that the lower segment of each of these curves takes the form of a vertical line at a specific value of the inducing-field luminance. This means that, if the inducing-field luminance is held constant at that specific value, further reductions in test-field luminance will produce no changes in the brightness of the test field. In other words, the values of test-field luminance at which the constant brightness curves become vertical lines represent the absolute thresholds for the detection of the test fields (shown by the dashed curve in Figure 2). The value of the absolute threshold, measured inside the hole in the annulus, is known to increase systematically with the luminance of the annulus (Cobb, 1916). The problem with which Jacobsen and Gilchrist (1988b) concern themselves has its origin in the mistaken assumption that the values of these absolute thresholds fall along a constant brightness curve. That this is not so can be seen in
Figure 2, and is easily demonstrated when one observes how the brightness of a disk of zero-luminance varies with the luminance of the annulus. Virtually all observers agree that the greater the luminance of the annulus, the blacker the hole in its center appears.

There seems to be no reason to assume, as do Jacobsen and Gilchrist, that Hess and Pretori's observers matched surrounds rather than test fields "in direct violation of the observer's instructions" (Jacobsen \& Gilchrist, $1988 \mathrm{~b}$, p. 10 ). Nor is there any other reason to doubt that Hess and Pretori's results mean exactly what they appear to mean: The ratio principle of brightness perception applies to a limited range of ratios. Outside of this range, systematic departures from brightness constancy may be found, as many experiments, including those of Jacobsen and Gilchrist (1988a, 1988b), have shown. The fact that Hess and Pretori's curves "cut blithely across some qualitative boundaries that other work had suggested ought to have distinct effects on the data" (Jacobsen \& Gilchrist, 1988b, p. 9) almost certainly means that, if they exist at all, these qualitative boundaries are irrelevant to brightness perception.

\section{REFERENCES}

Coвs, P. W. (1916). The effect on foveal vision of bright surroundings: IV. Journal of Experimental Psychology, 1, 540-566.

Fry, G. A. (1931). The stimulus correlate of bulky color. American Journal of Psychology, 43, 618-622.

Fry, G. A., ALPERN, M. (1953). The effect of a peripheral glare source upon the apparent brightness of an object. Journal of the Optical Society of America, 43, 189-195.

HeINEMANN, E. G. (1955). Simultaneous brightness induction as a function of inducing- and test-field luminances. Journal of Experimental Psychology, 50, 89-96.

HeinemanN, E. G. (1961). The relation of apparent brightness to the threshold for differences in luminance. Jourmal of Experimental Psychology, 61, 389-399.

HeinemanN, E. G. (1972). Simultaneous brightness induction. In D. Jameson \& L. M. Hurvich (Eds.), Handbook of sensory physiology: VII/4. Visual psychophysics (pp. 146-169). Berlin: Springer-Verlag. HELSON, H. (1943). Some factors and implications of color constancy. Joumal of the Optical Society of America, 33, 555-567.

Hess, C., \& Pretori, H. (1894). Messende Untersuchungen über die Gesetzmässigkeit des simultanen Helligkeits-kontrastes. Graefes Archiv fur Opthalmologie, 40, 1-24.

JACOBSEN, A., \& GILCHRIST, A. (1988a). The ratio principle holds over a million-to-one range of illumination. Perception \& Psychophysics, 43, $1-6$.

JaConsen, A., Gilchrist, A. (1988b). Hess and Pretori revisited: Resolution of some old contradictions. Perception \& Psychophysics, 43, 7-14.

JAENSCH, E. R., \& MülLer, E. A. (1920). Über die Wahrnehmungen farbloser Helligkeiten und den Helligkeitskontrast. Zeitschrift für Psychologie, 83, 266-341.

JAMESON, D., \& HuRVich, L. M. (1961). The complexities of perceived brightness. Science, 133, 174-179.

KATZ, D. (1935). The world of color (R. B. MacLeod \& C. W. Fox, Trans.). London: Kegan Paul, Trench, \& Trubner. (Original work published 1930)

WALLACH, H. (1948). Brightness constancy and the nature of achromatic colors. Journal of Experimental Psychology, 38, 310-324.

(Manuscript received June 8, 1988; revision accepted for publication July 1, 1988.) 